Smart Infrastructure and Construction Volume 170 Issue SC3

Briefing: UK-RAS white paper in robotics and autonomous systems for resilient infrastructure

Fuentes, Chapman, Cook et al.

ice proceedings
Proceedings of the Institution of Civil Engineers

Smart Infrastructure and Construction 170 September 2017 Issue SC3

Pages $72-79 \mathrm{https}: / /$ doi.org/10.1680/jsmic. 17.00013

Paper 1700013

Received 22/06/2017 Accepted 20/09/2017

Published online 27/10/2017

Keywords: field testing \& monitoring/risk \& probability analysis/tunnels \&

tunnelling

ICE Publishing: All rights reserved

\title{
Briefing: UK-RAS white paper in robotics and autonomous systems for resilient infrastructure
}

1 Raul Fuentes EUR ING, MSc, EngD, CEng MICE Associate Professor in Infrastructure Engineering, University of Leeds, West Yorkshire, UK (corresponding author: R.Fuentes@leeds.ac.uk)

2 Timothy Chapman BE, MSC, DIC, CEng, FICE, FIEI, FREng Director and London Infrastructure Leader, ARUP, London, UK

3 Michael Cook

Head of Transformation, KIER, Utilities Services, Bedfordshire, UK

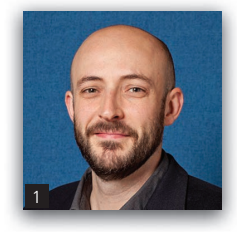

4 Jim Scanlan FRAeS

Professor of Aerospace Design, University of Southampton, Southampton, UK

5 Zhibin Li

Lecturer in Robotics and Control, University of Edinburgh, Edinburgh, UK

6 Robert C. Richardson FIMECHE, CENG, PhD, BEng Professor, University of Leeds, West Yorkshire, UK

This paper presents an extended briefing of the recently published UK-Robotics and autonomous systems (RAS) network Whie Paper in RAS for resilient infrastructure. It aims at setting out a vision of what RAS systems will be able to deliver in infrastructure, what are the current barriers and challenges to achieve that vision and what can the UK Government do to ensure that the UK remains at the forefront in this field.

\section{Introduction}

The infrastructure sector supports the entirety of the national GDP, without which, there would be no economic activity. The UK Government has recognised this and committed to spend over $£ 500$ billion on high-quality infrastructure projects by 2020-21 alone (HM Treasury and Infrastructure and Projects Authority, 2016). Outside the UK, as an illustration of the scale of the problem, the US road network requires US $\$ 134$ billion per year to maintain according to Chinowsky et al. (2013).

Our economic infrastructure system of systems is composed of the dense networks of energy, transport, water, waste, telecommunications and flood defences that provide the essential services on which people depend. Those networks are elderly and under heavy pressure as society demands ever-increasing levels of service from existing facilities. They are also highly interdependent, adding more complexity to the system (Eusgeld et al., 2011; Kröger, 2008; Thacker et al., 2017).

Key priorities of the infrastructure engineering sector include the affordability of deploying new facilities and reducing the cost of maintaining and improving existing systems. Upgrade of infrastructure can be driven by changing patterns of demands, such as the growing and ageing population or the introduction of new infrastructure technology.

An additional pressure is the need to mitigate and adapt infrastructure to the effects of climate change, which include decarbonisation of all aspects of infrastructure provisions, as well as adapting facilities to deal with the consequences of climate change, such as increased flood defences. To show the scale of the problem,
Chinowsky et al. (2013) noted that the road infrastructure in the US will require US $\$ 2 \cdot 8$ billion more than currently thought by 2050 if prices are not discounted in order to adapt to climate change: This is a significant increase that will mean even more efficiencies will need to be sought to optimise expenditure.

These ever-increasing complexity and demands of infrastructure are driving a trend toward automation of all parts of infrastructure provision and operation with significant opportunity for robotic solutions. In this paper, the authors understand automation as the process of developing activities or processes automatically, without human intervention in the field. Robots are the physical agents that are deployed to enable automation to occur in combination with other machines (e.g. PCs, wireless communication systems, and sensors) and software.

Robots have the benefit of being able to operate across the full range of infrastructure engineering (see Figure 1), for example, inspection, maintenance and repair task working in the air, on the ground, in water and underground. They also bring a number of distinct potential advantages over traditional human-based practices.

- Greater accuracy: Precise and repeatable operations beyond the capability of humans are achievable.

- No uncertainty of human factors: Repetitive and mundane operations can be delivered with greater repeatability.

- Faster operation: Activities can be performed in a shorter period of time.

- Improved safety: Humans do not need to undertake risky activities. 


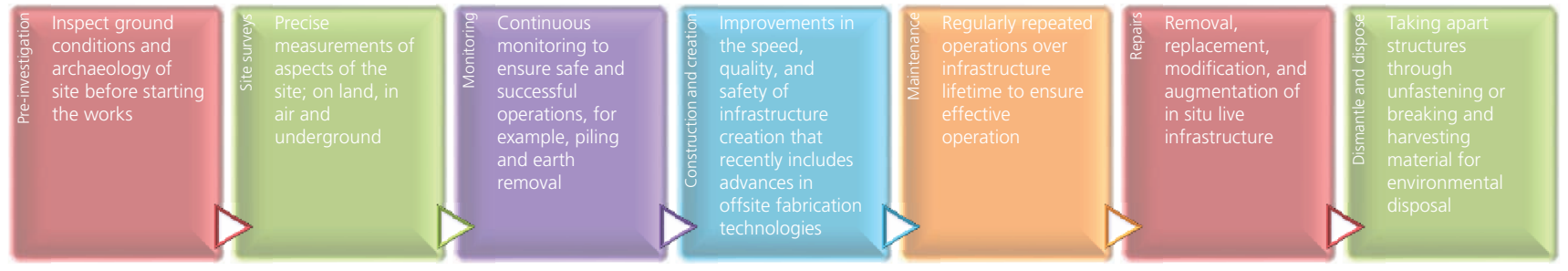

Figure 1. Standard tasks undertaken as part of infrastructure engineering

- Improved efficiency and higher productivity: The input energy and materials needed to create the same outcome are less, resulting not only in financial gains but also the environmental benefits of lower energy consumption and fewer wasted materials.

- Better jobs for humans: To free humans from the need to undertake dirty, dull and dangerous jobs.

- Proactive action: Robots can undertake more frequent inspections of difficult-to-access locations, catching defects early and preventing escalation of damage.

now-cost: The same outcome can be delivered with less cost using robots.

The convergence of robotics and autonomous systems (RAS) with Smart Infrastructure and its ability to embed intelligence into assets, extract intelligence from big data and the development of new materials and processes have begun to create a platform to overcome some of the complex engineering challenges associated with installing and maintaining infrastructure networks. The companies that successfully deploy and exploit RAS will be at the forefront of the fourth industrial revolution. In addition to providing an unparalleled customer experience, it is likely that these firms will unlock value chains that generate completely new economic activities.

This paper summarises the main points shown in the recently published UK-RAS white paper in robotics and autonomous systems for resilient infrastructure (Richardson et al., 2017). It provides a vision of how infrastructure will look like in the face of widespread robotic solutions. It also presents the current barriers for full deployment and provides some recommendations for the full exploitation of robotics in infrastructure in the UK and, by proxy, to the rest of the world.

\section{Vision}

The vision the white paper sets the scene for the rest of this paper and presents a new aspirational paradigm in the field of construction. This is one where infrastructure engineering is undertaken with zero disruption to human activity and zero environmental impact.

In this paradigm, cities will be proactively maintained by teams of autonomous robots that will generate and process information about the state of health of different assets and act on this information.
Current state-of-the-art applications have focused on inspection (e.g. Balaguer et al., 2002; Bock, 2007; Jahanshahi et al., 2009; Jiang et al., 2005; La et al., 2013; Lattanzi and Miller, 2015, 2017; Lee et al., 2012; De Paiva et al., 2006; Peel et al., 2016) with fewer applications of repair due to technology development and, in particular, challenges in robotic object manipulation (e.g. Roth et al., 1998). However, in the future, there will be no separation between sensing and repair; robot teams will be capable of performing both tasks seamlessly as researched in the self-repairing city project (Self Repairing Cities, EP/N010523/1 n.d.).

New infrastructure will be autonomously created by robots either built offsite and assembled in location operating as a manufacturing facility (e.g. Willmann et al., 2016) or fully created on-site where only prototypes have been created to date (e.g. Augugliaro et al., 2014; Bosscher et al., 2007; Erdine et al., 2017; Gardiner et al., 2016; Keating et al., 2017; Tay et al., 2017; Więckowski, 2017).

Infrastructure robots will draw on data from smart cities and autonomous cars using advanced communication systems and cloud technology, undertaking reasoning using sophisticated artificial intelligence algorithms, in full integration with ongoing developments such as Smart Cities (e.g. Ampatzidis et al., 2017; Ermacora et al., 2016; Foina et al., 2016; Huang et al., 2016; Salmerón-García et al., 2017), Building Information Modelling (e.g. Chuang et al., 2011; Edenhofer et al., 2016; Feng et al., 2015; Lundeen et al., 2017; Rausch et al., 2017; Schlette and Roßmann, 2017; Vähä et al., 2013), Big Data or the Internet of Things (e.g. Giyenko and Cho, 2017; Dos Santos et al., 2016; Torras, 2016). This future will result in a healthier, happier and more productive society.

However, this vision will need to tackle and overcome a series of challenges related to the infrastructure ecosystem within which robots will operate and resolve robotic science and technological challenges and socio-economic challenges as well. These are covered below.

\section{Infrastructure ecosystem challenges}

In the UK, the Government has committed to spend over $£ 100$ billion by $2020-21$ on infrastructure alone (HM Treasury and Infrastructure and Projects Authority, 2016). This is a significant step-change in the Government's previous proposals which on average means an investment of $£ 20$ billion per year from 2016: an 


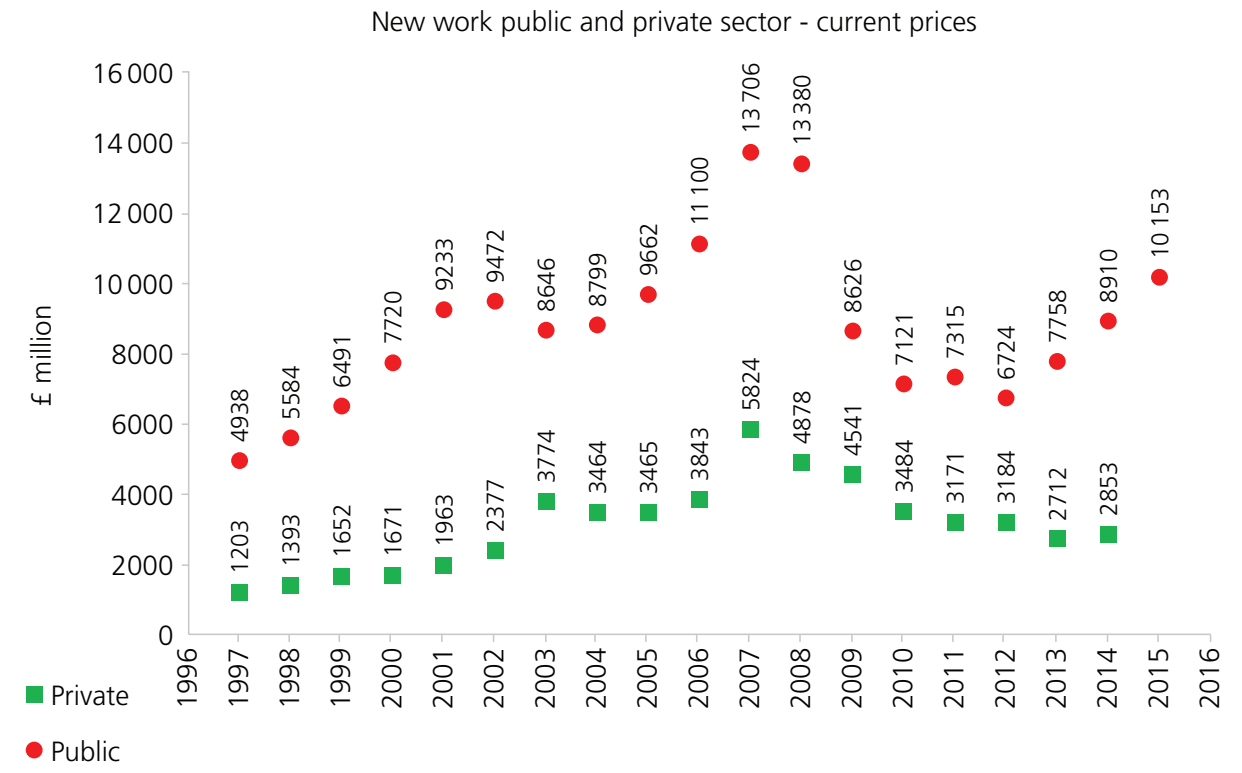

Figure 2. Trend of the construction industry's market size (HM Government, 2016)

approximately three-fold increase on the values from previous years and almost two times pre-crisis levels in 2007 (see Figure 2).

This increased Government investment is built around delivering improvements in four societal challenges (HM Infrastructure and Projects Authority, 2016), named below, to which robots and autonomous systems can contribute in different ways.

\section{- Supporting growth and creating jobs}

The use of robotics in construction will have an impact on the labour market and in construction. However, its net effect is still unclear. Deloitte shows that out of 2607000 jobs in real estate and construction, $34 \%$ are high risk, $15.5 \%$ are medium risk and $50.6 \%$ are low risk (Smith and Bishop, 2016) in terms of being lost to automation, although the figure is $24 \%$ at high risk according to PriceWaterhouseCoopers (Berriman and Hawksworth, 2017). However, research also shows that robotics creates jobs as shown by the International Federation of Robotics (International Federation of Robotics n.d.). For example, the US automotive industry installed more than 60000 industrial robots between 2010 and 2015 and the number of employees increased by 230000 in the sector.

\section{- Raising the productive capacity of the economy} It has been shown many times that expanding productive capacity requires investment in research and innovation. Equally, robotics has been identified as one of the most obvious vehicles to increase capacity. For example, structures that were not possible in the past could be possible today.

- Driving efficiency

Using the manufacturing industry as proxy, Boston Consulting Group (Sirkin et al., 2015) shows that 'as a result of higher robotics use, average manufacturing labour costs will be 33 percent lower in South Korea and to 25 percent lower in China, Germany, the US, and Japan than they otherwise would have been'. Similar efficiency benefits can be expected in the construction industry in the short to medium term, especially in sub-sectors like pre-fabrication, modular construction and off-site manufacturing where research and actual implementations are already underway (e.g. Bi et al., 2015). In the mid- to long-term, in situ fabrication will also be much quicker (e.g. Erdine et al., 2017; Keating et al., 2017; Lundeen et al., 2017; Tay et al., 2017).

- Boosting international competitiveness

The UK is a research power both in robotics and infrastructure subjects. For example, the Government has recently invested $£ 138$ million to increase infrastructure research capacity in the UK through the UKCRIC programme (UKCRIC - UK Collaboratorium for Research on Infrastructure and Cities n.d.). In the industrial sector, UK consultancies are among the biggest and most successful around the world. Jewell and Flanagan (2012) show that Construction Professional Services account for $£ 4.01$ billion (fourth of all service exports). However, UK contractors, compared to others in Europe, are less successful in exporting. Robotics presents an opportunity to provide a competitive advantage to contractors, while maintaining and enhancing the global standing of research institutions and consultancies alike.

A particular challenge of the construction industry is its fragmented taxonomy (see Figure 3 for details of the UK), and this is a worldwide phenomenon that acts as a barrier to innovation (Dulaimi et al., 2002; Häkkinen and Belloni, 2011). Most companies are very small SMEs that comprise the most significant financial share of the market, while only very few large companies 


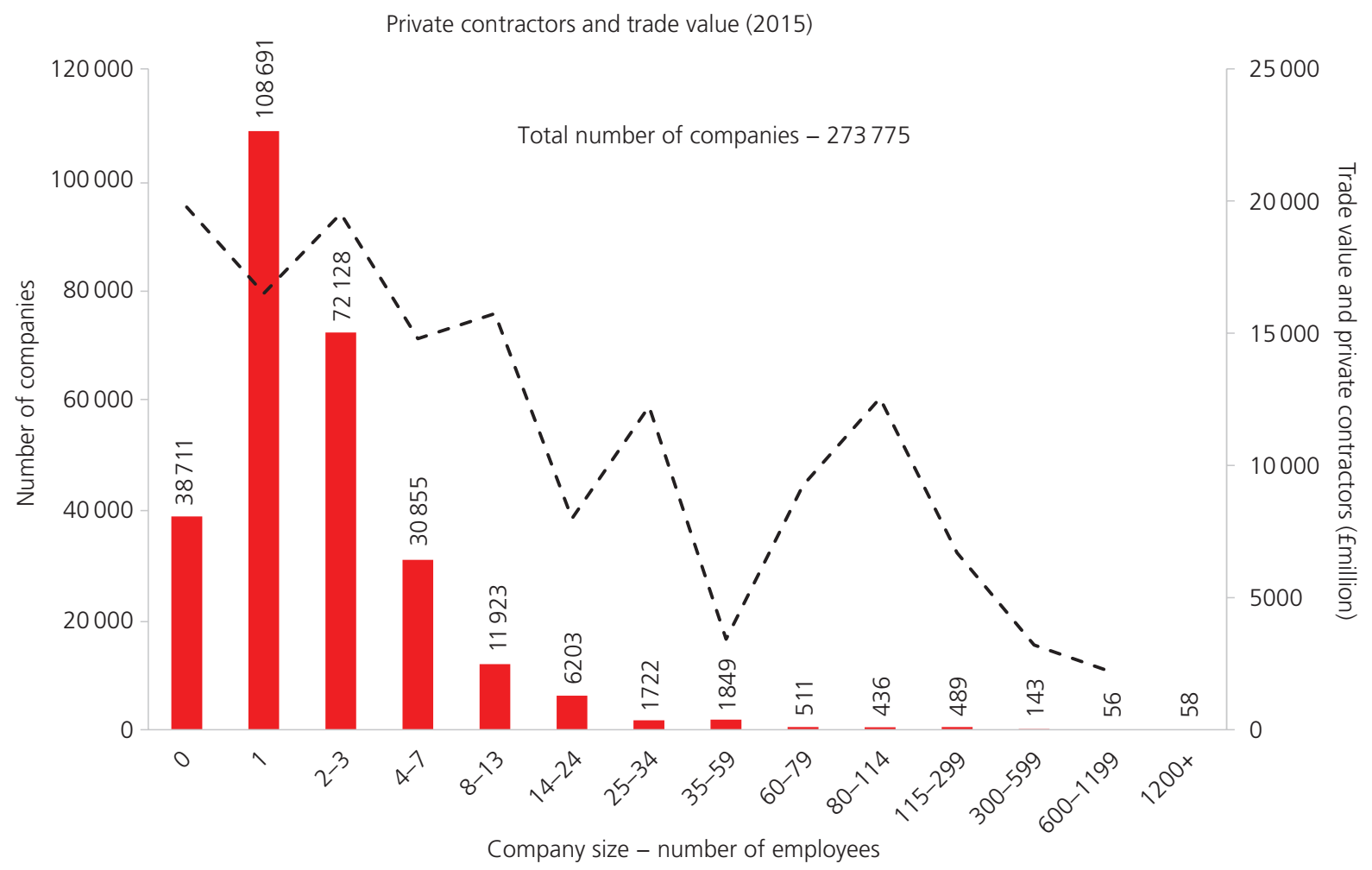

Figure 3. Fragmentation of the UK construction industry (HM Government, 2016)

employing more than 1200 employees exist and have a market share lower than $20 \%$. However, equally, small and medium-sized enterprises (SMEs) have the least financial prowess to invest in disruptive technologies such as robotics, placing them at a disadvantage. This is partly because the business models to date are not capable of capturing the potential benefits of these technologies, therefore making it harder to attract the necessary finance. There are new approaches to quantify the financial benefits of these investments. For example, Bi et al. (2015) carried out research showing and justifying how SMEs should invest.

Hence, to achieve the UK Government's intended benefits and to roll out robotics widely within the construction industry, significant investment will be required at all technology readiness levels (TRLs) spanning from fundamental research to maintain the UK's strong position to commercial enterprises. This will need to include public and private sectors, SMEs, large construction companies and universities.

Focus must be placed on maintaining and enhancing research in infrastructure robotics, where the UK is currently world-leading, while developing new construction robotics technologies that will give UK contractors a competitive advantage internationally. Additionally, substantial funds will need to be spent on training and making sure that the fragmented supply chain, consisting of small SMEs, is not left behind and can benefit from it as well. New business models will be needed to implement this future at industry level, which will require either significant internal investment or, more likely, pump-priming public money to promote this change.

\section{Robotic, scientific and technological challenges}

Seven robotic technological barriers are identified in the white paper (see Figure 4) that currently restrict the wider adoption of robotics technology for infrastructure delivery. They are termed here as Perch and Repair, Perceive and Patch, Construct and Confirm, Dismantle and Dispose, Plunge and Protect, and Fire and Forget and build on the Self-Repairing Cities project's initial proposal (Self Repairing Cities, EP/N010523/1 n.d.).

Application of these core robotic technologies is dependent on Data and Decisions (see Figure 4) obtained and processed locally or accessed remotely through, for instance, data 'cloud' technology with examples that were already provided (e.g. Chuang et al., 2011; Ermacora et al., 2016; Huang et al., 2016; Salmerón-García et al., 2017).

These challenges are the technological building blocks for the future of infrastructure robotics. Alongside technological challenges, it is also important to address the wider issues of openness and sharing; assurance and certification; security and resilience; and of public trust, understanding and skills (Lloyd's Register Foundation, 2016). 


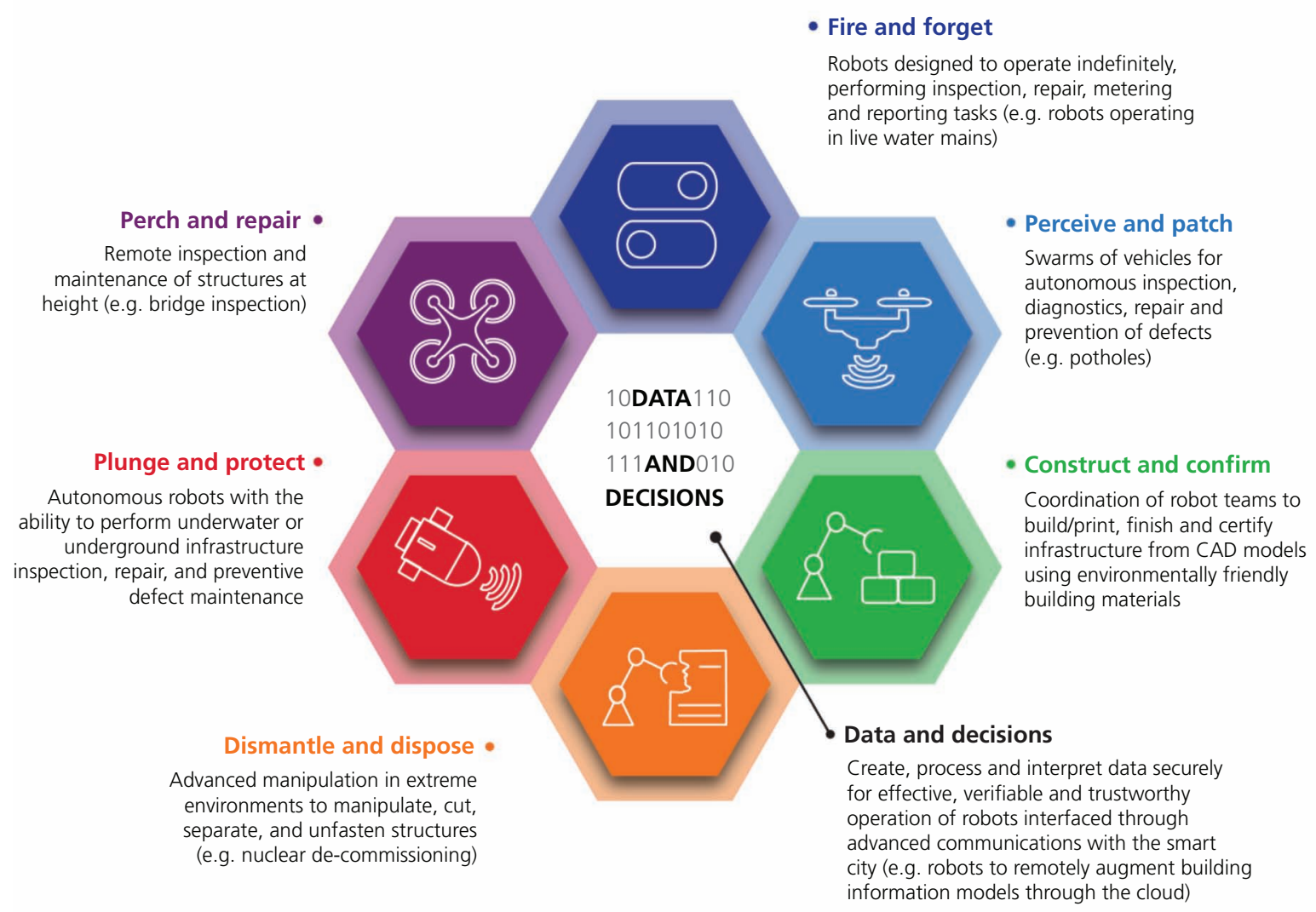

Figure 4. Technological challenges in infrastructure robotics

\section{Socio-economic challenges}

Humans, by nature, fear the unknown, especially when they see it as a threat to their livelihood and the comfort of the status-quo (Rotman, 2013). These fears are fuelled by the predictions of senior figures; the Governor of the Bank of England's was reported as predicting the loss of 15 million jobs to robots (Haldane, 2015). However, when it comes to technology advances, this fear is often based on false and uninformed constructs of reality and the future (Fuentes, 2016), although some authors suggest that this time, things may be different (Campa, 2015; Ford, 2015). This fear is not new, as exemplified in Bronte's quotation below, from the Industrial Revolution era, when the steam locomotive, the telegraph, the sewing machine or Edison's light bulb were invented and rapidly spread throughout the land.

“... these sufferers hated the machines which they believed took their bread from them: they hated the buildings which contained those machines; they hated the manufacturers who owned those buildings."

From Shirley: A Tale, by Charlotte Bronte, 1849

The introduction of any new technology, let alone one as radical as RAS, will always change the distribution of jobs in a sector. However, this need not be for the worse overall. In the infrastructure sector, many current jobs are dirty, dull and dangerous. Maintaining our buried infrastructure of pipes, cables and wires involves working in deep excavations; upgrading our electricity, communications and street lighting networks means working at heights; looking after our roads and railways can put people in the path of live traffic. All these activities put operatives and the public at risk of injury or worse. The time taken to finish many maintenance tasks is often dominated by routine preparatory or remedial work (i.e. digging holes and filling them back in), which either wastes the time of skilled workers or creates low-quality jobs that do not give workers the chance to become skilled. It is these jobs that robots should replace, freeing up our workforce to tackle the more complex, creative and challenging issues facing our ageing infrastructure. The infrastructure industry is desperately short of workers, particularly at higher skill levels across the world. For example, Tateyama (2016) highlights this in Japan and presents robotics as part of this solution. Additionally, reducing the unskilled workload will give the industry the opportunity to retrain existing workers rather than be forced to recruit internationally.

The design, manufacture, commissioning, supervision and maintenance of infrastructure robots will create a new industry 
with new jobs, as will adapting the infrastructure people have now to make it easier for the robots to navigate and operate. Research should tackle social issues head-on alongside technical research in collaboration with policymakers through bodies such as the Institute for Civil Engineering and the Royal Academy of Engineering in the UK.

It is important to consider environmental issues as part of the value of adopting RAS for infrastructure engineering. Proactive maintenance has the potential to identify and repair defects, quickly minimising damage and the scale of subsequent repair and allowing infrastructure assets to be kept in service for long. By increasing the reliability and resilience of infrastructure, it also minimises the environmental pollution caused by, for example, traffic congestion as a result of street works or the displacement of animals and materials from large excavation works. Improved resilience of pipe networks will help to conserve fresh water and prevent pollution of our natural environment by fugitive sewage.

\section{Recommendations}

The UK-RAS white paper builds the case for infrastructure robotics investment, developing a world-leading UK robotics sector that can assist the government in achieving its key strategic priorities: supporting growth and creating jobs; raising the productive capacity of the economy; driving efficiency; and boosting international competitiveness.

For its realisation, three key action priorities are proposed to accelerate the uptake of robotics within infrastructure engineering.

- Investment in interlinked basic research and technology transfer is required to pull advanced robotic technology into infrastructure engineering; only a small amount of UK Government-funded robotics research has been allocated to develop infrastructure robotics. Investment into the whole infrastructure supply chain will be needed to support uptake, training and new business models to accommodate the autonomous future.

- Industry and universities should work together to develop test facilities where infrastructure robots can be allowed to gracefully fail and be evaluated and improved. Current test facilities are small-scale, fragmented and uncoordinated and the industry will need financial and commercial incentives to share, operate and manage test facilities that advance the development of robust robotic solutions for the benefit of the sector. This will need to happen at three levels.

Lab scale: Specific elements of real infrastructure should be recreated in research lab environments (e.g. a pipe, a bridge bearing and wind turbine) incorporating some elements of the real operational environment, for example perturbation in temperature and wind conditions.

- Prototype scale: 1:1 large-scale testing facilities in dedicated research areas that are designed to stress test prototype systems in close to operational conditions, but under tightly controlled conditions enabling specific failure modes to be investigated (e.g. strong winds).

- Real-world scale (Living lab): Robots would be deployed on real assets under human-accessed controlled conditions to allow their operational performance to be stressed to graceful failure.

- Infrastructure robotics should be developed in partnership with the general public and community organisations to tackle perceived challenges around loss of jobs. Programmes should be put in place to train the next generation of robot-savvy infrastructure engineers, including advanced apprenticeships, degree programs and doctorial training schemes.

\section{Conclusions}

This paper is a summary of the findings of the UK-RAS white paper. It presents a vision of robotics in infrastructure and to reach that vision, shows the identified actions needed in seven main areas. It also provides a summary of recommended actions to the UK Government (as the target audience of the white paper) to implement in order to lead the way in infrastructure robotics.

\section{Acknowledgements}

The authors are grateful to the UK-RAS for their support in preparing the white paper. Equally, an immense thank you to all the contributing authors named in the white paper and the engineering and physical sciences research council (EPSRC) for funding the Infrastructure Grand Challenge 'Balancing the Impact of City Infrastructure Engineering on Natural Systems using Robots' (Self Repairing Cities, EP/N010523/1 n.d.).

\section{REFERENCES}

Ampatzidis Y, Bellis LD and Luvisi A (2017) iPathology: robotic applications and management of plants and plant diseases. Sustainability (Switzerland) 9(6).

Augugliaro F, Lupashin S, Hamer M et al. (2014) The flight assembled architecture installation: Cooperative contruction with flying machines. IEEE Control Systems 34(4): 46-64.

Balaguer C, Gimenez A and Abderrahim M (2002) ROMA robots for inspection of steel based infrastructures. Industrial Robot 29(3): 246-251.

Berriman R and Hawksworth J (2017) UK Economic OutlooK 4 - Will robots steal our jobs? The potential impact of automation on the UK and other major economies. See https://www.pwc.co.uk/economicservices/ukeo/pwcukeo-section-4-automation-march-2017-v2.pdf (accessed 20/06/2017).

Bi ZM, Liu Y, Baumgartner B et al. (2015) Reusing industrial robots to achieve sustainability in small and medium-sized enterprises (SMEs). Industrial Robot 42(3): 264-273.

Bock T (2007) Construction robotics. Autonomous Robots 22(3): 201-209.

Bosscher P, Williams RL II, Bryson LS and Castro-Lacouture D (2007) Cable-suspended robotic contour crafting system. Automation in Construction 17(1): 45-55.

Campa R (2015) Humans and Automata: A Social Study of Robotics. Chinowsky PS, Price JC and Neumann JE (2013) Assessment of climate change adaptation costs for the U.S. road network. Global Environmental Change 23(4): 764-773. 
Briefing: UK-RAS white paper in robotics and autonomous systems for resilient

infrastructure

Fuentes, Chapman, Cook et al.
Chuang TH, Lee BC and Wu IC (2011) Applying cloud computing technology to BIM visualization and manipulation. Proceedings of the 28 th International Symposium on Automation and Robotics in Construction, ISARC 2011

Dos Santos OL, Cury D, Rafalski J and David Netto Silveira P (2016) An IoT computational robotics learning laboratory in Vila Velha, Espirito Santo. Proceedings - 2016 11th Latin American Conference on Learning Objects and Technology, LACLO 2016.

Dulaimi MF, Ling FYY, Ofori G and De Silva N (2002) Enhancing integration and innovation in construction. Building Research and Information 30(4): 237-247.

Edenhofer S, Rädler S, Hoß M and Von Mammen S (2016) Self-organised construction with Revit. Proceedings - IEEE 1st International Workshops on Foundations and Applications of Self-Systems, FAS-W 2016.

Erdine E, Kallegias A, Moreira AFL, Devadass P and Sungur A (2017) Robot-aided fabrication of interwoven reinforced concrete structures. Communications in Computer and Information Science.

Ermacora G, Rosa S and Toma A (2016) Fly4SmartCity: a cloud robotics service for smart city applications. Journal of Ambient Intelligence and Smart Environments 8(3): 347-358.

Eusgeld I, Nan C and Dietz S (2011) System-of-systems approach for interdependent critical infrastructures. Reliability Engineering and System Safety 96(6): 679-686.

Feng C, Xiao Y, Willette A, McGee W and Kamat VR (2015) Vision guided autonomous robotic assembly and as-built scanning on unstructured construction sites. Automation in Construction 59: 128-138.

Foina AG, Sengupta R, Lerchi P, Liu Z and Krainer C (2016) Drones in smart cities: overcoming barriers through air traffic control research. 2015 Workshop on Research, Education and Development of Unmanned Aerial Systems, RED-UAS 2015

Ford M (2015) Rise of Robots. Basic Books.

Fuentes R (2016) Blog: Robots and the eternal technology anachronism Blog. See http://selfrepairingcities.com/blog/robots-and-the-eternaltechnology-anachronism/ (accessed 21/06/2017).

Gardiner JB, Janssen S and Kirchner N (2016) A realisation of a construction scale robotic system for 3D printing of complex formwork. ISARC 2016 - 33rd International Symposium on Automation and Robotics in Construction.

Giyenko A and Cho YI (2017) Intelligent UAV in smart cities using IoT International Conference on Control, Automation and Systems.

Häkkinen T and Belloni K (2011) Barriers and drivers for sustainable building. Building Research and Information 39(3): 239-255.

Haldane AG (2015) Labour's Share Speech given by Bank of England's Chief Economist and Executive Director.

HM Government (2016) Construction industry - Office for National Statistics. See https://www.ons.gov.uk/businessindustryandtrade/ constructionindustry (accessed 21/06/2017).

HM Infrastructure and Projects Authority (2016) National Infrastructure Delivery Plan 2016-2021.

HM Treasury and Infrastructure and Projects Authority (2016) National Infrastructure Pipeline 2016 - Publications - GOV.UK. Policy paper. See https://www.gov.uk/government/publications/nationalinfrastructure-pipeline-2016.

Huang X, Zhang J, Wu Q, Fan L and Yuan C (2016) A coarse-to-fine algorithm for registration in 3D street-view cross-source point clouds. 2016 International Conference on Digital Image Computing: Techniques and Applications, DICTA 2016.

International Federation of Robotics (n.d.) Robots Create Jobs! See https://ifr.org/robots-create-jobs (accessed 20/06/2017).

Jahanshahi MR, Kelly JS, Masri SF and Sukhatme GS (2009) A survey and evaluation of promising approaches for automatic image-based defect detection of bridge structures. Structure and Infrastructure Engineering 5(6): 455-486.
Jewell C and Flanagan R (2012) Measuring construction professional services exports: a case for change. Building Research and Information 40(3): 337-347.

Jiang B, Sample AP, Wistort RM and Mamishev AV (2005) Autonomous robotic monitoring of underground cable systems. 2005 International Conference on Advanced Robotics, ICAR '05, Proceedings.

Keating SJ, Leland JC, Cai L and Oxman N (2017) Toward site-specific and self-sufficient robotic fabrication on architectural scales. Science Robotics 2(5): eaam8986.

Kröger W (2008) Critical infrastructures at risk: A need for a new conceptual approach and extended analytical tools. Reliability Engineering and System Safety 93(12): 1781-1787.

La HM, Lim RS, Basily BB et al. (2013) Mechatronic systems design for an autonomous robotic system for high-efficiency bridge deck inspection and evaluation. IEEE/ASME Transactions on Mechatronics 18(6): $1655-1664$

Lattanzi D and Miller GR (2015) 3D scene reconstruction for robotic bridge inspection. Journal of Infrastructure Systems 21(2): 4014041.

Lattanzi D and Miller G (2017) Review of robotic infrastructure inspection systems. Journal of Infrastructure Systems 23(3): 4017004

Lee D, Kim G, Kim D, Myung H and Choi HT (2012) Vision-based object detection and tracking for autonomous navigation of underwater robots. Ocean Engineering 48: 59-68.

Lloyd's Register Foundation (2016) Foresight Review of Robotics and Autonomous Systems: Serving a Safer World.

Lundeen KM, Kamat VR, Menassa CC and McGee W (2017) Scene understanding for adaptive manipulation in robotized construction work. Automation in Construction 82: 16-30.

De Paiva EC, Azinheira JR, Ramos JG Jr, Moutinho A and Bueno SS (2006) Project AURORA: insfractructure and flight control experiments for a robotic airship. Journal of Field Robotics 23(3-4): 201-222.

Peel H, Morgan G, Peel C, Cohn A and Fuentes R (2016) Inspection robot with low cost perception sensing. ISARC 2016 - 33rd International Symposium on Automation and Robotics in Construction.

Rausch C, Nahangi M, Haas C and West J (2017) Kinematics chain based dimensional variation analysis of construction assemblies using building information models and 3D point clouds. Automation in Construction 75: 33-44.

Richardson R, Fuentes R, Chapman T et al. (2017) Robotics and Autonomous Systems for Resilient Infrastructure - UK RAS White Paper.

Roth H, Schilling K, Futterknecht S, Weigele U and Reisch M (1998) Inspection and repair robots for waste water pipes - a challenge to sensorics and locomotion. IEEE International Symposium on Industrial Electronics.

Rotman D (2013) How technology is destroying jobs. MIT Technology Review. See https:/www.technologyreview.com/s/515926/howtechnology-is-destroying-jobs/ (accessed 21/06/2017).

Salmerón-García JJ, van Den Dries S, Díaz-del-Río F et al. (2017) Towards a cloud-based automated surveillance system using wireless technologies. Multimedia Systems.

Schlette C and Roßmann J (2017) Model-based development of robotic systems and services in construction robotics. Advances in Intelligent Systems and Computing.

Self Repairing Cities, EP/N010523/1, E. project (n.d.) Self Repairing Cities. EPSRC project EP/N010523/1

Sirkin H, Zinser M and Ryan Rose J (2015) The Robotics Revolution: The Next Great Leap in Manufacturing - Boston Consulting Group.

Smith M and Bishop G (2016) Automation transforming UK industries. Deloitte, UK. See https://www2.deloitte.com/uk/en/pages/press-releases/ articles/automation-and-industries-analysis.html\# (accessed 20/06/2017).

Tateyama K (2016) Achievement and future prospects of ICT construction in Japan. Journal of Robotics and Mechatronics 28(2): 123-128.

Tay YWD, Panda B, Paul SC et al. (2017) 3D printing trends in building and construction industry: a review. Virtual and Physical Prototyping 12(3): 261-276 
Smart Infrastructure and Construction

Volume 170 issue SC3
Briefing: UK-RAS white paper in robotics

and autonomous systems for resilient

infrastructure

Fuentes, Chapman, Cook et al.
Thacker S, Pant R and Hall JW (2017) System-of-systems formulation and disruption analysis for multi-scale critical national infrastructures. Reliability Engineering and System Safety 167: 30-41.

Torras C (2016) Service robots for citizens of the future. European Review 24(1): 17-30.

UKCRIC UK (Collaboratorium for Research on Infrastructure and Cities) (n.d.). See http://www.ukcric.com/ (accessed 30/08/2017).

Vähä P, Heikkilä T, Kilpeläinen P, Järviluoma M and Gambao E (2013)

Extending automation of building construction - survey on potential sensor technologies and robotic applications. Automation in Construction 36: 168-178.

Więckowski A (2017) 'JA-WA' - a wall construction system using unilateral material application with a mobile robot. Automation in Construction 83: 19-28.

Willmann J, Knauss M, Bonwetsch T et al. (2016) Robotic timber construction - expanding additive fabrication to new dimensions. Automation in Construction 61: 16-23.

\section{How can you contribute?}

To discuss this paper, please email up to 500 words to the editor at journals@ice.org.uk. Your contribution will be forwarded to the author(s) for a reply and, if considered appropriate by the editorial board, it will be published as discussion in a future issue of the journal.

Proceedings journals rely entirely on contributions from the civil engineering profession (and allied disciplines).

Information about how to email your paper online is available at www.icevirtuallibrary.com/page/authors, where you will also find detailed author guidelines. 